\title{
INEQUALITY, POLARISATION AND REGIONAL MOBILITY IN THE EUROPEAN UNION
}

\author{
Roberto Ezcurra, \\ Carlos Gil \\ Pedro Pascual \\ Manuel Rapún \\ D-T.2004/03
}




\title{
Inequality, polarisation and regional
}

\author{
mobility in the European Union*
}

\author{
Roberto Ezcurra, Carlos Gil, Pedro Pascual and Manuel Rapún ${ }^{\dagger}$ \\ Department of Economics
}

Universidad Pública de Navarra

${ }^{*}$ The authors acknowledge the financial support from MCYT (Project BEC2002-03941) and the Fundación BBVA. In addition, the authors would like to thank Carlos Gradín for useful comments.

${ }^{\dagger}$ Postal address: Manuel Rapún, Department of Economics, Universidad Pública de Navarra, Campus de Arrosadia s/n. 31006 Pamplona (Spain). E-mail address: mrapun@unavarra.es. 


\begin{abstract}
This paper examines the distribution dynamics of regional per capita income in the European Union between 1977 and 1999. To achieve this aim, we combine a non-parametric approach with the information provided by various measures used in the literature on personal income distribution. The results obtained suggest that regional inequality and polarisation have decreased in the European context over the period considered. Likewise, the observed level of intradistributional mobility is relatively low. Furthermore, our findings reveal the important role played by the national component and the spatial dimension in the distribution dynamics.
\end{abstract}

Key words: Inequality, polarisation, mobility, regional per capita income, European Union.

JEL Code: O15, R11, R12. 


\section{Introduction}

Territorial imbalances, both international and interregional, are a permanent focus of attention, not only in the academic world but also in the political and social spheres. The existing empirical evidence shows a lack of balance in the spatial distribution of economic development, which is characterised by the existence of differences more or less relevant between the various geographical areas contemplated. In order to explain this situation, different factors need to be considered at once. Specifically, in addition to issues relating directly to the physical structure and natural resources of each area, the analysis must also take into account the consequences of certain historical events. It is also necessary to bear in mind the effects deriving from the workings of the economic system, the results of possible external shocks caused, for example, by technological progress, the decline of certain productive activities or the changes in international trade patterns.

From the equity-based perspective, however, it is hard to justify the marked differences in welfare levels that can exist between the different areas of a particular territory. It is for this reason that the basic texts of a large number of countries and supranational institutions, frequently mention among their priority objectives the need to contribute to the spatial balance of income distribution.

The European Union is no exception in this respect. Indeed, the reduction of regional disparities in development levels is directly related to some of the Union's basic underlying principles. In fact, there has been constant concern for backward or declining regions throughout the whole of the ongoing European integration process, even though, 
with the march of time, the measures taken to alleviate their situation have tended to vary considerably in their intensity. Thus, for example, in the preamble to the Treaty of Rome, there were already signs of interest on the part of the then six member States in strengthening "the unity of their economies (...), by reducing the differences existing between the various regions and the backwardness of the less favoured regions", though such concern is not reflected in the basic objectives of the recently created European Economic Community. Even though the project for European integration assumed that it would boost the growth potential of all member States, it was not until the adoption of the Single Act and the signing of the Maastricht Treaty that the need to guarantee economic and social cohesion within the European Union became part of the primary Community law. Various articles of the said treaty make specific reference to this issue. Article 2, for example, states that "The Community shall have as its task (...) to promote $(\ldots)$ a harmonious and balanced development of economic activities, (...), economic and social cohesion and solidarity among Member States". This idea is developed and reinforced in other parts of the same text, which specifies that the economic growth of the European Union must go hand in hand with the strengthening of internal cohesion and that the regional aspects of the problem require a commitment to continue and develop the lines of action already undertaken in the past.

Nevertheless, despite the fact that it is politically undesirable to allow too much inequality between the various geographical regions that make up the European Union, removing it is no easy task. In fact, the models offered in the economic literature on this topic are often contradictory in their explanations as to how economic integration 
processes affect changes in territorial inequality, and the empirical evidence presented so far has failed to prove conclusive (Abraham and Van Rompuy, 1995). By focusing exclusively on the final outcome of these processes, it is possible to identify two types of theories. On the one hand, some models claim that spatial disparities tend to decrease in the course of time as a result of the impact of market forces. However, other authors argue that a combination of various factors causes economic activity to concentrate in certain areas, thus giving rise to divergence. Therefore, according to Emerson et al. (1992), nominal convergence will help to achieve real convergence, so the integration process will tend to reduce existing differences in per capita income levels. On the other hand, Fujita, Krugman and Venables (1999) or Midelfart-Knarvik et al. (2000) claim that the development of the integration process will promote an accumulation of income in the more dynamic areas, as a result of externalities and agglomeration economies, which lead, in the final instance, to divergence and even to polarization (Krugman, 1991).

The increasing relevance of this topic is also closely linked to major advances in economic growth theory that have been made over the last twenty years, both on the theoretical and empirical side. Thus, in contrast to the traditional neoclassical model presented by Solow (1956) and Swan (1956), the endogenous growth models developed in the wake of the seminal work by Romer (1986) are based on the presence of constant or increasing returns to capital (Romer, 1987). The fundamental difference in these more recent contributions is that they abandon the restrictive interpretation of capital in the neoclassical model (physical capital) in favour of a wider definition that includes 
human capital (Lucas, 1988) and the development of innovations (Grossman and Helpman, 1994). These assumptions allows to invert the prediction of convergence of the neoclassical model, leading to the conclusion that the faster growth of rich economies causes inequality to increase over time. Obviously, it is worth finding out which of these models provides the most realistic picture. In particular, the convergence hypothesis can be used as a kind of test-bed that should enable us to test the empirical validity of the two theories. In fact, this theoretical debate has now moved into the regional context, without no winner has as yet been declared. Despite the enormous amount of literature generated by the issue, the controversy continues to exist.

In light of these considerations, most of the studies that have analysed regional disparities in per capita income in the European context apply the concepts of sigma convergence and beta convergence introduced by Barro and Sala-i-Martin (1991, 1992), combining the information provided by various dispersion statistics with the estimate of convergence equations ${ }^{1}$. However, as Quah (1993, 1996a,b; 1997) has repeatedly pointed out, not only does this approach raise a number of econometric problems, it also fails to capture a series of potentially interesting features of the dynamics of the distribution in question. In particular, this type of analysis provides only a partial view of the observed distribution, since it neglects to consider, for example, the fact that the various regions may shift their relative positions over the study period; thus it completely ignores the possibility of intradistributional mobility. This conventional approach also fails to inform about the possible existence of distinct clusters of regions with distinguishing features that set them apart from the rest of the population. 
Against this background, this paper analyses the distribution dynamics of regional per capita income in the European Union from 1977 to 1999. In doing so, we examine the main features of economic trends in the European regions during the period considered, focusing on inequality, polarisation and regional mobility. Our main purpose is to contribute to the understanding of territorial imbalances in the European context in terms of per capita income, a key variable in regional growth processes.

To address the limitations of conventional convergence studies, this paper follows in the main the non-parametric approach proposed by Quah $(1993,1996 a, b ; 1997)$ to analyse the evolution of the entire cross-section distribution ${ }^{2}$. Likewise, to complete the results, we take a series of measures from the literature on personal income distribution and apply them to the regional context.

Any attempt to study regional disparities within the European Union meets with the problem of lack of regional data. Some authors, [Barro and Sala-i-Martin (1991), Sala-iMartin (1996), Fagerberg and Verspagen (1996)] choose to limit the number of countries in the sample for the sake of extending the period of observation. Others, [Neven and Gouyette (1995), López Bazo et al. (1999)] prefer to cover a wider geographical area, despite the fact that this restricts the length of the study period. In this respect, this paper represents a break from the existing literature on this subject. The use of data supplied by Cambridge Econometrics has enabled us to work with figures of population and value added at market prices for 197 NUTS2 regions throughout the period 1977$1999^{3}$.

The paper is organised as follows. Section 2, contains an analysis of regional per 
capita income disparities in the European context, using information obtained from various measures commonly used in the traditional literature on inequality. Section 3 investigates the dynamics of the distribution of interest, focusing particularly on polarisation and regional mobility. To further round off the results obtained thus far, section 4 examines the roles of the national component and the spatial dimension in territorial imbalances in per capita income observed within the European Union. Section 5 presents the main conclusions.

\section{Regional inequality}

We begin by examining the evolution of spatial disparities in per capita income in the European Union from 1977 to 1999. In contrast to the procedure adopted in conventional convergence analysis, this paper will approach the issue by calculating a series of indicators traditionally used to study the personal income distribution. However, since our unit of reference is the region and not the individual, we will then introduce into the analysis the relative frequencies of each observation. Thus, all the indicators calculated will be statistics weighted by the population share of the different regions ${ }^{4}$. However, studies that focus on the convergence hypothesis tend usually to ignore differences in population, income or employment across the various regions considered ${ }^{5}$. This omission has particular repercussions in the European context, since it means that the analysis assigns the same weight to quite different regions ${ }^{6}$.

Within the literature on personal income distribution, it is a well-known fact that results may differ, at times substantially, according to which measures are used in the 
analysis. Given the obvious difficulty that arises from the fact that different indicators may give different orderings of the distributions to be compared, it would seem reasonable to check the robustness of our results against different inequality measures. According to this procedure, in this paper we have examined regional disparities in per capita income in the European Union by means of the information provided by the Gini index, $G(x)$, and the two measures proposed by Theil (1967) within the information theory context, $T(0)$ and $T(1)^{7}$. We also take into account the coefficient of variation, $C V_{\omega}(x)$, and the standard deviation of the $\operatorname{logs}, S D_{\omega}(\log x)$, two measures of dispersion that are common in descriptive statistics and widely used in the convergence literature to capture the concept of sigma convergence ${ }^{8}$. All the indices selected are independent of scale and size of population and, except for the standard deviation of the logs, they all fulfil the Pigou-Dalton transfer principle for the whole definition domain of income ${ }^{9}$.

Figure 1 presents the evolution of the inequality indices just mentioned. The results indicate a decrease in dispersion within the distribution between 1977 and 1999. Indeed, the various indices fell by between $9 \%$ and $24 \%$ over the twenty-three years considered. This does not imply a steady rate of reduction in disparities throughout the period, however. In fact, by whichever measure of inequality it is viewed, the main reduction in inequality is seen to have taken place in the late seventies, followed by a period of stagnation in the next two decades. Moreover, though it is not ordinally equivalent to the other measures, the standard deviation of the logs can be seen to behave in a qualitatively similar fashion. Note, also, that the Theil indices do not appear to be particularly sensitive to the shares used to weight inequality. This is simply an indication 
of a high level of positive correlation between population shares and income shares in the European Union. Indeed, the average of the correlation coefficient between the two variables for the $1977-1999$ period is $0.90^{10}$.

\section{[INSERT FIGURE 1 AROUND HERE]}

It is well known, however, that the evolution of regional per capita income levels depends on changes in income and/or population in the various regions considered. This may have important implications, moreover, since, from the above analysis, it is impossible to determine whether the observed reduction in regional disparities is due, say, to lower relative income growth in more developed regions or to a reduction in the population of poorer regions.

Various authors have examined this issue using different measures that provide a picture of the spatial distribution of income and population over a given period of time ${ }^{11}$. It would clearly be rash, however, to link trends in regional per capita income disparities to the information provided by this type of indicators. For a better understanding of this idea, let us consider a hypothetical situation in which there is an exchange of population between two regions with widely differing incomes. In a case such as this, any of the measures of concentration typically proposed in the literature will remain unaltered over the period, even though it is obvious that changes in the distribution of the population must have an impact on observed inequality.

To overcome this problem, therefore, we now perform an alternative analysis in which we estimate the level of inequality in two virtual distributions. In the first, regional in- 
come is kept constant at the level for the start of the period and only population varies over time; in the second, population is kept constant and only regional incomes are allowed to vary throughout the twenty-three years contemplated. These two virtual distributions enable us to determine the level of inequality that would have been registered if there had been no change over time in the relative trends of the two selected variables. The results of this exercise are reported in Table 1, where it can be seen that, in the first virtual distribution, inequality as measured by the Gini index increases between 1977 and 1999, in contrast to the second distribution where the level of dispersion diminishes over the same period. Specifically, the Gini index in each case varies by $8 \%$ and $-14 \%$ respectively over time. This indicates that changes in population distribution have not contributed to the reduction of regional disparities previously detected within the European Union, so the observed process of convergence has therefore taken place without any major reductions in the populations of the less developed regions. On the contrary, the analysis carried out suggests that the reduction in inequality is mainly due to changes in the regional income distribution.

\section{[INSERT TABLE 1 AROUND HERE]}

It may also be worth comparing the results obtained so far with others based on simple statistics that ignore regional population shares, as is common practice in conventional studies of the convergence hypothesis. For this, we calculate two further unweighted measures of dispersion used to capture the concept of sigma convergence: the coefficient of variation and the standard deviation of the logs. The results, reported 
in Figure A1 show that, in contrast to what was noted from the various indicators calculated in this section, regional disparities remained practically constant or may even have risen slightly between 1977 and 1999. In any event, other considerations notwithstanding, this is a clear indication of how the results of the analysis may be influenced by methodological decisions relating to the inclusion or not of regional weightings.

To complete the results obtained so far, we have estimated the boxplots corresponding to the regional distribution of per capita income for different years of the study period (Figure 2). Before discussing the results, it may be useful to describe the various components of a conventional boxplot, which is simply a two-dimensional representation of a set of descriptive statistics. The box represents the interquartile range, where the first and third quartiles coincide with its lower and upper edges respectively. The box, therefore, contains $50 \%$ of the probability mass of the distribution. The median is represented by the horizontal line inside the box, while the two horizontal lines that appear attached to the box are known as adjacent values ${ }^{12}$. Finally, the observations that appear beyond the adjacent values are outliers, represented in the Figure 2 as small circles.

\section{[INSERT FIGURE 2 AROUND HERE]}

According to our results, there was a slight reduction in the interquartile range of the distribution of per capita income in the European Union over the period as a whole. This means that there was a relative increase in the concentration of $50 \%$ of the density around the median, mainly due to the performance of regions situated at the upper end 
of the distribution. All of this is consistent with the information given by Figure 1 . Likewise, the distance between the extreme values is also seen to have been maintained throughout the period analysed.

\section{The distribution dynamics.}

In the previous section we have carried out a first analysis of the regional disparities observed in the European context using the information provided by different statistical measures of position and dispersion. However, the various statistics calculated so far do not supply an accurate description of the regional per capita income distribution. To overcome this problem, we will now estimate the density functions of the distribution analysed. Following common practice in the literature, we will use non-parametric estimation techniques, thus avoiding the need to specify any particular functional form beforehand. This kind of approach undoubtedly offers major advantages in the present context, given that parametric approximations are lacking in generality and flexibility.

Figure 3 shows the density functions, both simple and weighted by population shares, of the regional distribution of per capita income ${ }^{13}$. The $\mathrm{x}$ axis represents the regional per capita income normalised (taking 100 as the European average) and the y axis shows the density associated. Estimates are based on calculations using Gaussian kernel functions. The optimal smoothing parameter value is also determined in each case, following Silverman $(1986)^{14}$.

[INSERT FIGURE 3 AROUND HERE] 
The results obtained after introducing the relative frequencies into the analysis reveal significant differences in the densities estimated over the period analysed. As Figure 3 shows, the European regions have experienced different growth patterns over the twentythree years considered, and display a tendency to cluster into different income classes. Thus, the existence of various local maxima is a constant in the distribution analysed. This kind of scenario is consistent with the emergence of convergence clubs (Baumol, $1986)^{15}$

The initial situation has not remained stable through time, however. Thus, the information given by Figure 3 suggests that, in 1977, some of the regions situated at the lower end of the distribution had managed to catch up the cluster around the European average, while others had fallen into what we might call a poverty trap. This second mode is composed by Portuguese and Spanish regions. It suggests that it might be possible to interpret the bimodal distribution observed in 1977 for the whole European Union as the weighted sum of two different unimodal densities. Twenty-three years on, however, the situation has changed considerably. In 1999, the estimated density function actually features two local maxima, just as it did in 1977. Unlike what happened in the first year of the study period, however, in addition to the usual grouping of regions around the European average, there is a new pole formed by regions at the upper end of the distribution. However, it is important to note that these regions are characterised by a degree of spatial concentration considerably more reduced than that corresponding to the second local maximum observed in 1977. Nevertheless, in 1999, there remains a large probability mass in levels below $75 \%$ of average per capita income. This is an 
indication of the difficulties faced at the end of the nineties by various low per capita income regions to improve their relative positions.

Note also, however, that throughout the period analysed, there has been an increase in the probability mass concentrated around the European average, resulting from weight losses at both ends of the distribution. The information summarised in Table A1 confirms this observation. Thus, in 1977, for example, $55 \%$ of the European population lived in regions with a per capita income level between $75 \%$ and $125 \%$ of the European average, while twenty-three years later, in 1999, the percentage had risen to $59 \%$. Similar results are obtained for other per capita income intervals considered. These findings are also consistent with the information yielded by the boxplots presented previously (Figure 2).

The estimated density functions, meanwhile, suggest the existence of some degree of polarisation in regional per capita income distribution over the period contemplated. However, it is not possible with a non-parametric analysis to obtain precise quantitative information on polarisation changes over time. To overcome this problem, we will now apply the approach proposed by Esteban and Ray (1994) and Esteban, Gradín and Ray (1999).

Following Esteban and Ray (1994), we can measure the polarisation of a given distribution $f$ according to the following expression:

$$
P^{E R}(\alpha, \rho)=\sum_{j=1}^{m} \sum_{k=1}^{m} p_{j}^{1+\alpha} p_{k}\left|y_{j}-y_{k}\right|
$$

where, for the purposes of this paper, $y_{j}$ and $p_{j}$ denote respectively the per capita income and the population share corresponding to group $j$. Likewise, $\alpha \in[1,1.6]$ is a 
parameter that reflects sensitivity to polarisation. Nevertheless, before applying this measure, it is necessary to define a simplified representation of the original distribution in a series of exhaustive and mutually exclusive groups, $\rho$. This will involve some degree of error, however, as this grouping will generate some loss of information, depending on the degree of income dispersion in each of the groups considered. Taking into account this idea, the measure of generalised polarisation proposed by Esteban, Gradín and Ray (1999) is obtained after correcting the $P^{E R}$ index applied to the simplified representation of the original distribution with a measure of the grouping error. Nonetheless, when dealing with personal or spatial income distributions, there are no unanimous criteria for establishing the precise demarcation between different groups. To address this problem, Esteban, Gradín and Ray (1999) follow the methodology proposed by Aghevli and Mehran (1981) and Davies and Shorrocks (1989) in order to find the optimal partition of the distribution in a given number of groups, $\rho^{*}$. This means selecting the partition that minimises the Gini index value of intragroup inequality, $G(f)-G\left(\rho^{*}\right)^{16}$. The measure of generalised polarisation proposed by Esteban, Gradín and Ray (1999), therefore, is given by:

$$
P^{E G R}\left(f, \alpha, \rho^{*}, \beta\right)=P^{E R}\left(\alpha, \rho^{*}\right)-\beta\left[G(f)-G\left(\rho^{*}\right)\right]
$$

where $\beta \geq 0$ is a parameter that informs about the weight assigned to the error term in expression (2).

We will now apply this methodology to examine the evolution of regional polarisation within the European Union between 1977 and 1999. Our aim is to analyse the degree of polarisation that exists after finding the optimal partition that minimises inequality 
due to intragroup dispersion. Figures 4 and 5 report the results obtained when this criterion is used to divide the European regional per capita income distribution into two and three groups. In our analysis we have contemplated different degrees of sensitivity to polarisation. Specifically, $\alpha=1,1.3,1.6$. Likewise, as in Esteban, Gradín and Ray (1999), in all the cases $\beta=1$.

\section{[INSERT FIGURE 4 AROUND HERE]}

Figure 4 shows a decline in the bipolarisation of the distribution of regional per capita income in the European Union over the period as a whole ${ }^{17}$. Indeed, the $P^{E G R}$ values decreased over the twenty-three years considered by between $20 \%$ and $29 \%$, according to the degree of sensitivity to polarisation considered in each case $\mathrm{e}^{18}$. The evolution of $P^{E G R}$ has not remained uniform throughout the whole period, however. In fact, four distinct phases can be observed, whatever degree of sensitivity to polarisation is contemplated. Thus, regional bipolarisation rose during the late seventies, reaching its maximum level in 1979. This upward trend was to change in the eighties, however, when the main reduction in $P^{E G R}$ took place. From the early to mid nineties, there was again a slight increase in bipolarisation, though this was followed from 1996 onwards by what may have been the start of a new phase, characterised by a decrease in $P^{E G R}$. This pattern over time clearly shows that bipolarisation did not evolve parallel to regional inequality. Therefore, this fact underlines the need for separate analyses of the two phenomena, such as we have undertaken in this paper.

[INSERT FIGURE 5 AROUND HERE] 
Figure 5 reports on the evolution of regional polarisation when the initial distribution is split into three groups ${ }^{19}$. As in the previous case, it is possible to observe an overall decline in regional polarisation in the European context during the 1977-1999 period. $P^{E G R}$ values, in particular, register decreases of $14 \%$ to $20 \%$, over the twenty-three years contemplated, depending on the value assigned to the $\alpha$ parameter. Note that, when the initial distribution is split into three groups, the resulting reduction in polarisation is lower on all indices than it was with the previous two-group split. This decline was not uniform throughout the study period, however. Though regional polarisation remained practically constant throughout the seventies, there was a change of trend in the eighties, when practically the total reduction in $P^{E G R}$ took place, the lowest value being registered in 1990 followed by a slight increase in the nineties. It is worth noting, however, that, unlike what happens with bipolarisation, the evolution of regional polarisation in the three-group case is somewhat similar to those of regional inequality.

The density functions estimated in Figure 3 give a first impression of the external shape of the distribution for each year of the period analysed. The indices calculated in Figures 4 and 5, likewise, inform about the degree and evolution of regional polarisation. This type of analysis, however, is based on a series of cross-sections of the distribution examined, and does not, therefore, take into account that the different economies may modify over time their relative positions in terms of per capita income. To address this shortcoming and to complete the results obtained so far, we will now examine the intradistributional mobility of regional per capita income distribution in the European Union between 1977 and 1999 . 
Most of the papers that have studied this issue are based on discrete transition matrices, obtained by dividing the distribution into a series of exhaustive and mutually exclusive classes $^{20}$. This approach entails a problem, however, since the results it yields are sensitive to the way in which the original distribution is divided up. Nevertheless, since there is no procedure for determining the optimum number of classes in each case, the researcher must decide arbitrarily ${ }^{21}$. To address this problem, Quah (1996b, 1997) suggests substituting the transition matrix with a stochastic kernel to reflect the probabilities of transition between a hypothetically infinite number of classes, reducing their size infinitesimally ${ }^{22}$. According to Quah (1996b, 1997), the stochastic kernel can be obtained by estimating the density function of the distribution over a given period, $t+k$, conditioned on the values corresponding to a previous period, $t$. Specifically, the joint density function at moments $t$ and $t+k$ is estimated and then divided by the implicit marginal distribution in order to obtain the corresponding conditional probabilities.

Figure 6 shows the stochastic kernel estimated for the whole sample period $(t=1977$ and $t+k=1999)^{23}$. This three-dimensional graph can be interpreted as a transition matrix with an infinite number of classes, that informs about the probabilities associated with each pair of values in the first and last years of the study period. In other words, the stochastic kernel gives us, as does a discrete transition matrix, the probability distribution of 1999 per capita income for regions with a given value in 1977 . High levels of probability are represented by the peaks on the graph. Thus, if the probability mass is concentrated around the main diagonal, the intradistributional dynamics are characterised by a high level of persistence in the relative positions of the regions over 
time and, therefore, low mobility. If, on the other hand, the density is located mainly on the opposite diagonal to the main diagonal, this would indicate that regions situated at both extremes of the distribution exchange their relative positions over time. Finally, the probability mass could, in theory, accumulate parallel to the $t$ axis. This would reflect the existence of a convergence process of regional per capita incomes throughout the study period. In order to aid interpretation of the graph, Figure 6 also includes the related contour plot, on which the lines connect points at the same height on the three-dimensional kernel.

\section{[INSERT FIGURE 6 AROUND HERE]}

Figure 6 shows the probability mass concentrated around the main diagonal. This illustrates the limited degree of mobility in regional per capita income distribution in the 1977-1999 period. European regions, therefore, tend generally to maintain their relative positions over the twenty-three years considered. Likewise, our findings also reveal that regions differ in their mobility patterns according to their level of development. Thus, regions with a per capita income around the European average register a greater degree of mobility over time. Regions situated at the extremes of the distribution, on the other hand, are characterised by more persistence in their relative positions throughout the period contemplated. Indeed, the information supplied by Figure 6 in this respect indicates that high income regions are comparatively less mobile than low income regions ${ }^{24}$.

We now estimate the corresponding ergodic distribution by iteration of the stochastic 
kernel until the convergence of the process is reached. Given that this is, by definition, a continuous distribution, it can be represented graphically (Figure 7). As shown, the corresponding ergodic distribution is characterised by a single local maximum located around the European average (unimodality). This situation contrasts with the information yielded by the density functions estimated in Figure 3 for various years between 1977 and 1999. According to these, regional per capita income distribution features various modes throughout the period considered, which appears to suggest a tendency of the European regions to cluster into different income classes. At this point, however, a word of warning is required: comparisons between Figure 7 and the density functions estimated previously should be based only on the shape of the distribution, since there is no point in comparing the level of density that appears on the vertical axis. In addition, it is worth noting that the fact that the greater part of the probability mass in Figure 7 is concentrated around the European average highlights the existence of future development opportunities, that might help to reduce existing territorial imbalances in terms of per capita income in the European context ${ }^{25}$.

[INSERT FIGURE 7 AROUND HERE]

\section{Determinants of the distribution dynamics: the national component and the spatial dimension}

To enhance the results achieved so far, in this section we will examine the role of the national component and the spatial dimension in the dynamics of the regional 
per capita income distribution in the European Union between 1977 and 1999. In a break from the standard practice in the literature, we will approach this issue using a series of instruments proposed by Quah (1996b, 1997) and introduced in the previous section, which will provide a fairly accurate estimation of the change that occurs in the distribution under study when various factors, in addition to regional per capita income, are introduced into the analysis.

Since the pioneer study by Molle, Van Holst and Smit (1980), the literature on spatial disparities in the European context has emphasised the importance of the specific features of various countries in regional growth processes ${ }^{26}$. It is therefore reasonable to assume that the national component may play a major role in the dynamics of regional per capita income distribution in the European Union throughout the period of observation. In order to analyse the importance of the so-called country effect, following Quah (1996c), we have constructed a conditioned distribution, obtained by normalising the per capita income of each region according to the average per capita income of the country to which it belongs, excluding the region in question.

On the other hand, so far we have considered the various regions as isolated units, and have thereby disregarded the strictly spatial dimension. No major problems should arise when using this approach, as long as the evolution of each region, in economic terms, is independent of the behaviour of the remaining regions over time. However, this does not seem a very realistic assumption within the context of the integration process currently underway in Europe, which is characterised overall by the decreasing relevance of national frontiers and a continual increase in the degree of interaction among 
regions. It is, therefore, reasonable to suppose that the per capita income level of a given region might be linked to that of another regions. Indeed, a detailed analysis of regional per capita income levels confirms the truth of such an assumption. Specifically, a clear positive spatial relationship among neighbouring areas is evident in both 1977 and 1999, indicating an overall similarity in per capita income levels between adjacent regions. The traditional literature on economic convergence has tended to examine this undeniably interesting issue by applying a set of techniques adopted from spatial econometrics $^{27}$. In this paper, however, we base our analysis of the subject on a new conditional distribution, obtained in this case by normalising the per capita income of each region according to the average per capita income of its adjacent regions.

The two conditioned distributions that we have defined can be intuitively interpreted as that part of the initial distribution that remains unexplained by the national component and the various factors relating to the spatial location of the regions considered. For a more precise understanding of this idea, let us first imagine a situation in which the country effect and the spatial dimension have no impact at all on the distribution dynamics of regional per capita income, so that regions that are richer (poorer) than the European average will also be richer (poorer) than their national average and their neighbouring regions. In this hypothetical scenario, the initial distribution would coincide with the conditioned distributions. If, on the other hand, the national component and the spatial dimension were to play a significant role, we might expect richer (poorer) regions to register a level of per capita income similar to the average of the regions with which they are grouped according to political or geographical criteria. 
The proposal made by Quah (1996c) is to analyse these issues by estimating various transition matrices. The shortcomings of this approach are well known, however; the researcher must first group the sample regions into an arbitrary number of classes. To overcome the problems involved in using discrete transition matrices, we have opted in this paper to use stochastic kernels and contour plots instead ${ }^{28}$.

Before going on to discuss the outcomes obtained, it might be worth clarifying a few points relating to the interpretation of stochastic kernels and contour plots in this context. Within this framework, these instruments provide information concerning the probabilities of transition between the initial distribution and the conditioned distribution, and not between two moments of time as in the previous case. Thus, if the factors considered do not help to explain the distribution dynamics, the probability mass should cluster around the main diagonal ${ }^{29}$. If, on the other hand, the national component and the spatial dimension are determinant in explaining the evolution of the distribution analysed, the density will tend to cluster parallel to the axis corresponding to the initial distribution and around the average.

Figure 8 reports the results obtained when this method is used to examine the impact of the country effect on the distribution dynamics of regional per capita income in the European Union between 1977 and 1999. To construct the stochastic kernel and the contour plot, we have considered the data on all twenty-three years of the period between 1977 and 1999. The results thus obtained highlight the importance of the national component in this context. Though with certain exceptions, the empirical evidence generally points to relatively substantial differences in the distribution of regional per 
capita income between a typical country and the European Union as a whole. However, close analysis of the graphs in Figure 8 allows to qualify this conclusion. Indeed, the national component appears to have more impact among regions with low or medium levels of development, given that their per capita income generally tends to coincide with the national average. However, at the upper end of the distribution, the probability mass appears to be approaching the main diagonal. This suggests that regional per capita income tends to be less related with the national average in regions with high levels of development.

\section{[INSERT FIGURE 8 AROUND HERE]}

We now use this same method to determine the impact of spatial factors relating to the geographical location of the various regions considered. We have estimated again the stochastic kernel and the contour plot for the initial and conditioned distributions over the whole of the twenty-three years contemplated. The results, shown in Figure 9, are largely consistent with those reported earlier for the national component. They clearly highlight the major role played by the spatial dimension in the dynamics of regional per capita income over the 1977-1999 period. As in the previous case, regions with low or medium development levels are characterised by sharing a similar per capita income with adjacent regions. In any event, for high per capita income values, the probability mass again appears to be approaching the main diagonal. Thus, regions situated at the upper end of the distribution tend, with certain exceptions, to have a higher level of regional per capita income than the adjacent regions. Therefore, the empirical evidence suggests 
that regions with low and medium levels of development have a greater tendency to cluster geographically than regions with high per capita incomes ${ }^{30}$.

\section{[INSERT FIGURE 9 AROUND HERE]}

\section{Conclusions}

In this paper we have examined the evolution of inequality, polarisation and mobility in regional per capita income distribution in the European Union between 1977 and 1999.

The results obtained reveal an overall reduction in regional inequality over the study period. The greater part of this reduction took place at the end of the seventies. However, regional disparities did not experience major changes throughout the next couple of decades, coinciding with the advances in the European integration process. These results, obtained using population-weighted regional data, differ from those reached when the evolution of dispersion in the distribution was analysed by means of unweighted statistics, which is common practice in most of the convergence literature. This fact underlines the importance of the inclusion or not of weightings in this type of analysis.

Meanwhile, the estimated density functions reveal the tendency of the European regions to cluster into different income classes over the sample period. Likewise, the share of population situated around the European average increased between 1977 and 1999 . Indeed, according to our results, regional polarisation in the European Union diminished over the period, irrespective of the number of groups considered in the analysis and the 
value adopted by the parameter of sensitivity to polarisation in the measure used to quantify this phenomenon.

Another aim of this paper was to examine the degree of mobility in the distribution of regional per capita income. The results obtained using a non-parametric approach suggest a relatively low level of intradistributional mobility. The European regions, therefore, tend on the whole to maintain their relative positions in terms of per capita income over the twenty-three years considered. Our analysis also reveals the existence of different mobility patterns among the various regions according to their development degree. Indeed, regions with per capita income levels around the European average exhibit greater mobility over time in comparison with those situated at each extreme of the distribution. In particular, there appears to be less mobility among high income than among low income regions.

Finally, the analysis carried out shows the major role played by the national component in explaining regional disparities in per capita income in the European Union. Thus, per capita income growth patterns in the European context are closely linked to country-specific features relating, for example, to historical, social and institutional factors. Our findings, meanwhile, confirm that there exists a clear spatial association between neighbouring areas, evidenced by the fact that adjacent regions tend on the whole to share similar development levels. Moreover, regions with relatively low and medium income per capita have a greater tendency towards geographical clustering than regions situated at the upper end of the distribution. 


\section{Notes}

${ }^{1} \mathrm{~A}$ review of this literature and the principle results obtained can be found in Armstrong (2002), Terrasi (2002) or Ezcurra (2004).

${ }^{2}$ In addition to Quah (1993, 1996a,b,c; 1997), see also Bianchi (1997), López-Bazo et al. (1999), Johnson (2000) or Tsionas (2000), among others.

${ }^{3}$ The data provided by Cambridge Econometrics are based mainly on information supplied by REGIO, the Eurostat regional database. REGIO, however, is seriously lacking in some respects, especially when it comes to data relating to the late seventies and early eighties. For this reason, and because of the need to work with complete series of regional data for a sufficient number of NUTS2 regions over time, Cambridge Econometrics has opted to complete REGIO data with alternative national statistics and interpolation methods. Lack of complete series has obliged us to exclude from our study the countries incorporated into the European Union in 2004, the Länder of former East Germany, the French overseas departments and the Spanish territories in North Africa. Likewise, monetary variables have been converted into constant 1990 euros, by applying the corresponding deflators, thus enabling us to compare data for different years in real terms.

${ }^{4}$ Note that this is equivalent to perform an analysis in individual terms, assuming that all the inhabitants of a region enjoy the same income. This, however, does not make up for the lack of data on personal income distribution within each of the regions concerned, which is something that must be kept in mind when it comes to carry out a normative evaluation of the results obtained in this paper.

${ }^{5}$ There are, nevertheless, some exceptions. See, for example, Salas (2002) or Goerlich (2003).

${ }^{6}$ In population terms, for example, the Finnish region of Aland in 1999 registered a population of 26.000, versus the more than 11 million of Ille de France.

${ }^{7}$ In particular,

$$
\begin{aligned}
& G(x)=\frac{\sum_{i=1}^{n} \sum_{j=1}^{n} p_{i} p_{j}\left|x_{i}-x_{j}\right|}{2 \mu} \\
& T(0)=-\sum_{i=1}^{n} p_{i} \log \left(\frac{x_{i}}{\mu}\right)
\end{aligned}
$$

and

$$
T(1)=\sum_{i=1}^{n} p_{i}\left(\frac{x_{i}}{\mu}\right) \log \left(\frac{x_{i}}{\mu}\right)
$$

where $x_{i}$ and $p_{i}$ denote respectively the per capita income and the population share of region $i$, with $\mu=\sum_{i=1}^{n} p_{i} x_{i}$.

${ }^{8}$ In contrast to the procedure adopted in conventional convergence analyses, for the purposes of this paper, both statistics were calculated after including the corresponding weightings.

${ }^{9}$ This means that any transfer of income from a rich region to a poorer region that fails to invert their relative positions does not necessarily imply a decrease in $S D_{\omega}(\log x)$, (Cowell, 1995).

${ }^{10}$ This suggests, furthermore, that similar results would have been obtained if we had chosen to weight the regions by their income share.

${ }^{11}$ See, for example, Villaverde (2003).

${ }^{12}$ Specifically, if $Q_{1}$ and $Q_{3}$ denote the first and third quartiles of the distribution respectively, the lower adjacent value is given by $Q_{1}-1,5 \times\left(Q_{3}-Q_{1}\right)$, while the upper adjacent value is given by 
$Q_{3}+1,5 \times\left(Q_{3}-Q_{1}\right)$. The distance between adjacent values, therefore, is the interval defined by $\left[Q_{1}-1,5 \times\left(Q_{3}-Q_{1}\right), Q_{3}+1,5 \times\left(Q_{3}-Q_{1}\right)\right]$.

${ }^{13}$ Though density functions were estimated for each year of the period analysed, to save space, we present only those of 1977, 1980, 1985, 1990, 1995 and 1999. The rest are available from the authors upon request.

${ }^{14}$ In particular, see Silverman (1986), p. 47. Readers interested in the methodological details might consult, the monographs of Scott (1992), Wand and Jones (1994) or Simonoff (1996), among others.

${ }^{15} \mathrm{~A}$ number of authors have investigated the possibility of the existence of convergence clubs in various geographical areas and time periods using a range of methodological options. In relation to this, see Baumol and Wolff (1988), Durlauff and Johnson (1996) or Quah (1996b,1997), among others.

${ }^{16}$ For further details on this point, see Esteban, Gradín and Ray (1999).

${ }^{17}$ In the two-group case, the optimal partition of the distribution is characterised by the fact that the income value that separates the two groups coincides with the average per capita income. When our 197 regions are made to form two groups following this criterion, it is possible on average to account for $70 \%$ of the total inequality as measured by the Gini index. The amount of internal inequality left unexplained by the grouping is therefore the $30 \%$.

${ }^{18}$ To check the robustness of this result, we have also calculated the measure of bipolarisation proposed by Wolfson (1994), which is given by:

$$
P^{W}=2 \frac{\mu}{m}\left[1-2 L\left(\frac{1}{2}\right)-G\right]
$$

where $\mu$ and $m$ are the mean and median of the distribution, respectively. $L\left(\frac{1}{2}\right)$ is the ordinate of the Lorenz curve corresponding to the median. The results obtained show an $18 \%$ decline in the $P^{W}$ value between 1977 and 1999 .

${ }^{19}$ The three-group representation explains on average the $85 \%$ of the total inequality measured by the Gini index, versus the $70 \%$ explained in the previous partition. The internal dispersion left unexplained by this grouping, therefore, is the $15 \%$. These results clearly show that increases in explanatory power diminish as the number of groups considered increases. For further information on this point, see Ezcurra (2004).

${ }^{20}$ For the European case Fingleton et al. (1996) and Cuadrado, Mancha and Garrido (2002) estimates various transition matrices to analyse regional mobility in terms of per capita income. Likewise, LópezBazo et al. (1999) apply this instrument to the examination of regional mobility in the distribution of product per worker.

${ }^{21}$ See Kremer, Onatski and Stock (2001).

${ }^{22}$ See Stockey and Lucas (1989). For a formal definition, interested readers may also consult Durlauf and Quah (1999).

${ }^{23}$ Gaussian kernel functions were used in all cases, while the smoothing parameter was selected following Silverman (1986), p. 86. Finally, all estimations were made using the the code proposed by Shuetrim (1999) to obtain the bivariate density function.

${ }^{24}$ Some caution is advisable when interpreting these results, however. In fact, the characteristics of regional per capita income distribution in the European Union are such that there is a higher proportion of regions located around the mean than at either end of the distribution. It comes as no great surprise, therefore, that it is precisely those regions in the middle of the distribution that register the highest level of mobility over the study period.

${ }^{25}$ It is obvious, however, that the findings obtained from the analysis of Figures 6 and 7 are determined by the dynamics of regional per capita income over the whole of the period analysed. We therefore decided to repeat the analysis using only data for the subperiods 1977-1988 and 1988-1999. The results are very similar to those already discussed and are therefore not included to save space.

${ }^{26}$ See also Sala-i-Martin (1996), Rodríguez-Pose (1999) and Ezcurra et al. (2004), among others.

${ }^{27}$ See, for example, Fingleton and McCombie (1998), López-Bazo et al. (1999) or Fingleton (1999). 


\footnotetext{
${ }^{28}$ Stochastic kernels and contour plots are used by Overman and Puga (2002) to investigate the origin of the disparities in regional unemployment rates in the European Union. See also Fingleton and López-Bazo (2003).

${ }^{29}$ In the discrete case, the corresponding transition matrix ought to coincide with the identity matrix.

${ }^{30}$ In light of these results, we decided to make a joint analysis of the roles played in this setting by the national component and the spatial dimension. For this we constructed another conditional distribution by normalising the per capita income of each region according to the average per capita income of the adjacent regions that form part of the same country. The results of this further analysis are shown in Figure A2. The graphs included are very similar to those in Figure 9, which contributes to confirm the results obtained earlier.
}

\section{References}

ABRAHAM, F. and VAN ROMPUY, P. (1995) Regional Convergence in the European Monetary Union, Papers in Regional Science, 74, pp. 125-142.

AGHEVLI, B. and MEHRAN, F. (1981) Optimal Grouping of Income Distribution Data, Journal of the American Statistical Association, 76, pp. 22-26.

ARMSTRONG, H. W. (2002) European Union Regional Policy Reconciling the Convergence and Evaluation Evidence, in J. R. CUADRADO and M. PARELLADA, (Eds.): Regional Convergence in the European Union: Facts, Prospects and Policies, pp. 231-272. Berlin: Springer-Verlag.

BARRO, R. and SALA-I-MARTIN, X. (1991) Convergence across States and Regions, Brooking Papers on Economic Activity, 1, pp. 107-182.

BARRO, R. and SALA-I-MARTIN, X. (1992) Convergence, Journal of Political Economy, 100, pp. 407-443.

BAUMOL, W. J. (1986) Productivity Growth, Convergence and Welfare, American Economic Review, 76 (5), pp. 1072-1085.

BAUMOL, W. J. and WOLFF, E. N. (1988) Productivity Growth, Convergence and Welfare Reply, American Economic Review, 78, pp. 1155-1159.

BIANCHI, M. (1997) Testing for Convergence Evidence from Nonparametric Multimodality Tests, Journal of Applied Econometrics, 12, pp. 393-409.

COWELL, F. (1995) Measuring Inequality, 2nd Edition, LSE Handbooks in Economics. London: Prentice Hall.

CUADRADO, J. R., MANCHA, T. and GARRIDO, R. (2002) Regional Dynamics in the European Union Winners and Losers, in J. R. CUADRADO and M. PARELLADA (Eds.): Regional Convergence in the European Union: Facts, Prospects and Policies, pp. 23-52. Berlin: Springer-Verlag.

DAVIES, J. B. and SHORROCKS, A. F. (1989) Optimal Grouping of Income and Wealth Data, Journal of Econometrics , 42, pp. 97-108.

DURLAUF, S. N. and JOHNSON, P. A. (1996) Local versus Global Convergence across National Economies, NBER Working Papers 3996, Cambridge. 
EMERSON, M., GROS, D., ITALIANER, A., PISANI-FERRY, J. and REICHENBACH, H. (1992) One market, one money. Oxford: Oxford University Press.

ESTEBAN, J. M. and RAY, D. (1994) On the Measurement of Polarization, Econometrica, 62 (4), pp. 819-851.

ESTEBAN, J. M., GRADÍN, C. and RAY, D. (1999) Extension of a Measure of Polarization with an application to the income distributions of five OECD countries, Luxembourg Income Study Working Paper Series 218, Maxwell School of Citizenship and Public Affairs. Syracuse University. (ftp //lissy.ceps.lu/218.pdf).

EZCURRA, R. (2004) Desigualdad, polarización y movilidad regional en la Unión Europea, Ph. Dissertation, Universidad Pública de Navarra.

EZCURRA, R., GIL, C., PASCUAL, P. and RAPÚN, M. (2004) Regional inequality in the European Union: does industry mix matter?, Regional Studies, forthcoming.

FAGERBERG, J. and VERSPAGEN, B. (1996) Heading for Divergence. Regional Growth in Europe reconsidered, Journal of Common Market Studies, 34, pp. 431-448.

FINGLETON, B. (1999) Estimates of time to economic convergence an analysis of regions of the European Union, International Regional Science Review, 22, pp. 5-35.

FINGLETON, B., LEWNEY, R. and PINELLI, D. (1996) Regional Growth and Convergence, The Single Market Review, subseries VI, vol. 1. London: Kogan Page-Earthscan.

FINGLETON, B. and MCCOMBIE, J. (1998) Increasing returns and economic growth some evidence for manufacturing from the European Union regions, Oxford Economic Papers, 50, pp. 89-105.

FINGLETON, B. and LÓPEZ-BAZO, E. (2003) Explaining the distribution of manufacturing productivity in the EU regions, in B. FINGLETON (Ed.): European Regional Growth, pp. 375-410. Berlin: Springer-Verlag.

FUJitA, M., KRUGMAn, P. and VEnABLES, A. (1999) The Spatial Economy. Cambridge: MIT Press.

GOERLICH, F. J. (2003) Weighted samples, kernel density estimators and convergence", Empirical Economics, 28, pp. 335-351.

GROSSMAN, G. and HELPMAN, E. (1994) Endogenous Innovation in the Theory of Growth, Journal of Economic Perspectives, 8, pp. 23-44.

JOHNSON, P. A. (2000) A Nonparametric Analysis of Income Convergence Across the US States, Economics Letters, 69, pp. 219-223.

KREMER, M., ONATSKI, A. and STOCK, J. (2001) Searching for prosperity, Carnegie-Rochester Conference Series on Public Policy, 55, pp. 275-303.

KRUGMAN, P. (1991): Geography and Trade. Cambridge: MIT Press.

LÓPEZ-BAZO, E., VAYA, E., MORA, A. and SURIÑACH, J. (1999) Regional Economic Dynamics and Convergence in the European Union, The Annals of Regional Science, 33, pp. 343-370. 
LUCAS, R. (1988) On the Mechanics of Economic Development, Journal of Monetary Economics, 22, pp. 3-42.

MIDELFART-KNARVIK, K., OVERMAN, H., REDDING, S. and VENABLES, A. (2000) The Location of European Industry, Economic Papers, 142, Directorate General for Economic and Financial Affairs, European Commission.

MOLLE, W., VAN HOLST, B. and SMIT, B. (1980) Regional Disparity and Economic Development in the European Community. Farnborough: Saxon House.

NEVEN, D. and GOUYETTE, C. (1995) Regional Convergence in the European Community, Journal of Common Market Studies, 33, pp. 47-65.

OVERMAN, H. and PUGA, D. (2002) Regional unemployment clusters, Economic Policy, 34, pp. 115-147.

QUAH, D. (1993) Empirical cross-section dynamics in economic growth, European Economic Review, 37, pp. 426-434.

QUAH, D. (1996a) Twin Peaks Growth and Convergence in Models of Distribution Dynamics, The Economic Journal, 106, pp. 1045-1055.

QUAH, D. (1996b) Empirics for Economic Growth and Convergence, European Economic Review, 40, pp. 1353-1375.

QUAH, D. (1996c) Regional convergence clusters across Europe, European Economic Review, 40, pp. 951-958.

QUAH, D. (1997) Empirics for Growth and Distribution Stratification, Polarization and Convergence Clubs, Journal of Economic Growth, 2, pp. 27-59.

RODRÍGUEZ-POSE, A. (1999) Convergence or Divergence? Types of Regional Responses to Socio-Economic Change in Western Europe, Tijdschrift voor Economische en Sociale Geografie, 90, pp. 363-378.

ROMER, P. (1986) Increasing returns and long-run growth, Journal of Political Economy, 94, pp. 1002-1037.

ROMER, P. (1987) Growth Based on Increasing Returns due to Specialization, American Economic Review, 77, pp. 56-62.

SALA-I-MARTIN, X. (1996) Regional Cohesion. Evidence and Theories of Regional Growth and Convergence, European Economic Review, 40, pp. 1325-1352.

SALAS, R. (2002) Multilevel interterritorial convergence and additive multidimensional inequality decomposition, Social Choice and Welfare, 19, pp. 207-218.

SCOTT, D. W. (1992) Multivariate Density Estimation Theory, Practice and Visualization. New York: John Wiley and Sons.

SHUETRIM, G. (1999) Gauss Routines to Estimate Univariate and Bivariate Kernel Densities, http://ideas.repec.org/c/apr/aprsft/cd 0003.html.

SILVERMAN, B. W. (1986) Density Estimation for Statistics and Data Analysis, Monographs on Statistics and Applied Probability 26. London: Chapman and Hall. SIMONOFF, J. S. (1996) Smoothing Methods in Statistics. Berlin: Springer- 
Verlag.

SOLOW, R. (1956) A Contribution to the Theory of Economic Growth, The Quarterly Journal of Economics, 70, pp. 65-94.

STOCKEY, N. L. and LUCAS, R. E. (1989) Recursive Methods in Economic Dynamics. Cambridge: Harvard University Press.

SWAN, T. (1956) Economic Growth and Capital Accumulation, Economic Record, 32, pp. 334-361.

TERRASI, M. (2002) National and Spatial Factors in EU Regional Convergence , 185209, in J. R. CUADRADO and M. PARELLADA (Eds.): Regional Convergence in the European Union: Facts, Prospects and Policies, pp. 185-209. Berlin: Springer-Verlag.

THEIL, H. (1967) Economics and Information Theory. Amsterdam: North Holland.

TSIONAS, E. G. (2000) Regional Growth and Convergence: Evidence from the United States, Regional Studies, 34 (3), pp. 231-238.

VILLAVERDE, J. (2003) Regional convergence, polarisation and mobility in the European Union, European Integration, 25, pp. 73-86.

WAND, M. P. and JONES, M. C. (1994) Kernel Smoothing. London: Chapman and Hall.

WOLFSON, M. (1994) When Inequalities Diverge, American Economic Review, 84 (2), pp. 353-358.

\section{Appendix}

The 197 territorial units considered in the paper are:

Belgium: Bruxelles-Brussel, Antwerpen, Limburg, Oost-Vlaanderen, Vlaams Brabant, West-Vlaanderen, Brabant Wallon, Hainaut, Liège, Luxembourg and Namur. Denmark. Germany: Stuttgart, Karlsruhe, Freiburg, Tübingen, Oberbayern, Niederbayern, Oberpfalz, Oberfranken, Mittelfranken, Unterfranken, Schwaben, Berlin, Bremen, Hamburg, Darmstadt, Giessen, Kassel, Braunschweig, Hannover, Lüneburg, Weser-Ems, Düsseldorf, Köln, Münster, Detmold, Arnsberg, Koblenz, Trier, Rheinhessen-Pfalz, Saarland and Sch.-Holstein. Greece: Anatoliki Makedonia, Kentriki Makedonia, Dytiki Makedonia, Thessalia, Ipeiros, Ionia Nisia, Dytiki Ellada, Sterea Ellada, Peloponnisos, Attiki, Voreio Aigaio, Notio Aigaio and Kriti. Spain: Galicia, Asturias, Cantabria, País Vasco, Navarra, La Rioja, Aragón, Madrid, Castilla-León, Castilla-la Mancha, Extremadura, Cataluña, Com. Valenciana, Baleares, Andalucía, Murcia and Canarias. France: Île de France, Champagne-Ard., Picardie, Haute-Normandie, Centre, BasseNormandie, Bourgogne, Nord-Pas de Calais, Lorraine, Alsace, Franche-Comté, Pays 
de la Loire, Bretagne, Poitou-Charentes, Aquitaine, Midi-Pyrénées, Limousin, RhôneAlpes, Auvergne, Languedoc-Rousillon, Provence-Alpes-Côte d'Azur and Corse. Ireland: Border-Midland and Western and Southern and Eastern. Italy: Valle d'Aosta, Piemonte, Liguria, Lombardia, Trentino-Alto Adige, Veneto, Friuli-Venezia Giulia, Emilia-Romagna, Toscana, Umbria, Marche, Lazio, Abruzzi, Molise, Campania, Puglia, Basilicata, Calabria, Sicilia and Sardegna. Luxembourg. Netherlands: Groningen, Friesland, Drenthe, Overijssel, Gelderland, Flevoland, Utrecht, Noord-Holland, ZuidHolland, Zeeland, Noord-Brabant and Limburg. Austria: Burgenland, Niederöster., Wien, Kärnten, Steiermark, Oberösterreich, Salzburg, Tirol and Vorarlberg. Portugal: Norte, Centro, Lisboa e Vale do Tejo, Alentejo, Algarve, Açores and Madeira. Finland: Itä-Suomi, Väli-Suomi, Pohjois-Suomi, Uusimaa, Etelä-Suomi and Aland. Sweden: Stockholm, Östra Mellansverige, Sydsverige, Norra, Mellansverige, Mellersta Norrland, Övre Norrland, Smaland med oarna and Västsverige. United Kingdom: Tees Valley and Durham, Northumberland et al., Cumbria, Cheshire, Greater Manchester, Lancashire, Merseyside, East Riding, North andorkshire, South Yorkshire, West andorkshire, Derbyshire, Leicestershire, Lincolnshire, Hereford et al., Shropshire, West Midlands, East Anglia, Bedfordshire, Essex, Inner London, Outer London, Berkshire et al., Surrey, Hampshire, Kent, Avon et al., Dorset, Cornwall, Devon, West Wales, East Wales, North East Scotland, Eastern Scotland, South West Scotland, Highlands and Islands and Northern Ireland.

[INSERT FIGURE A1]

[INSERT FIGURE A2]

[INSERT TABLE A1] 


\section{Figures and Tables}

Figure 1: Regional inequality $(1977=100)$.

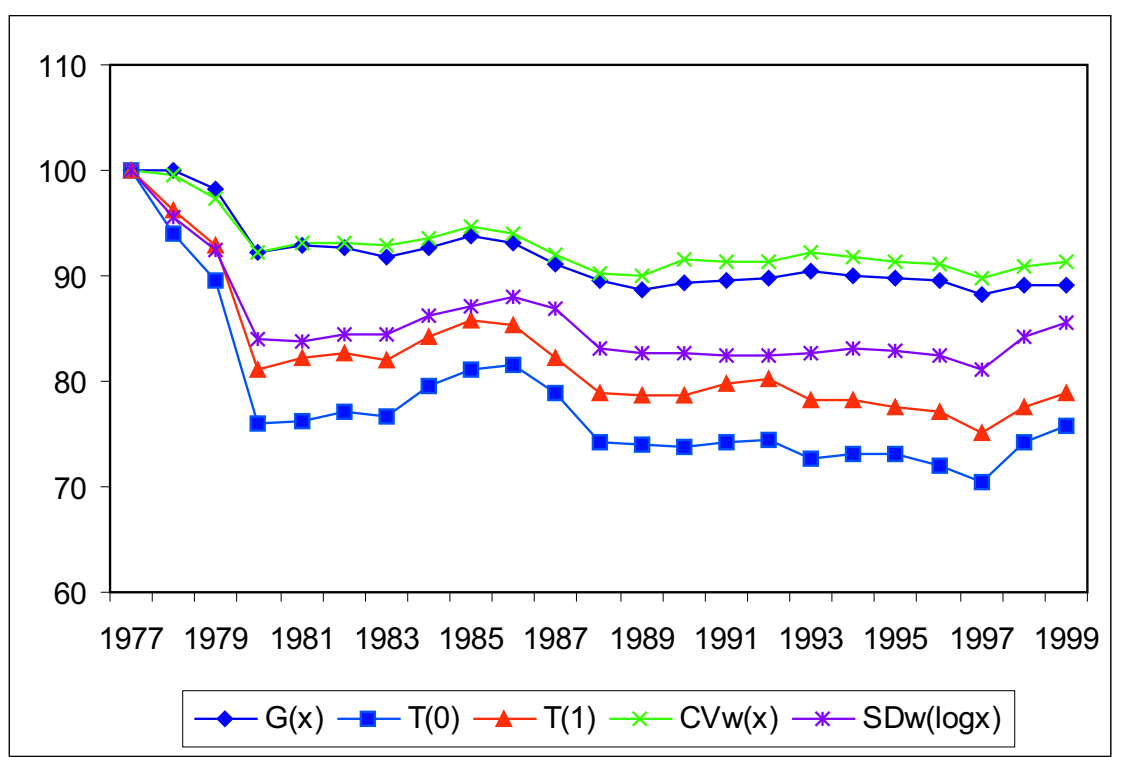

Table 1: Regional inequality: the role of changes in income and population.

\begin{tabular}{c|c|c|c} 
Inequality & Original & Income fixed & Population fixed \\
\hline 1977 & 0.2089 & 0.2089 & 0.2089 \\
1980 & 0.1926 & 0.2216 & 0.1860 \\
1985 & 0.1959 & 0.2284 & 0.1799 \\
1990 & 0.1866 & 0.2271 & 0.1745 \\
1995 & 0.1877 & 0.2243 & 0.1809 \\
1999 & 0.1860 & 0.2265 & 0.1799 \\
\hline
\end{tabular}


Figure 2: Boxplots. (Data weighted according to population shares.)

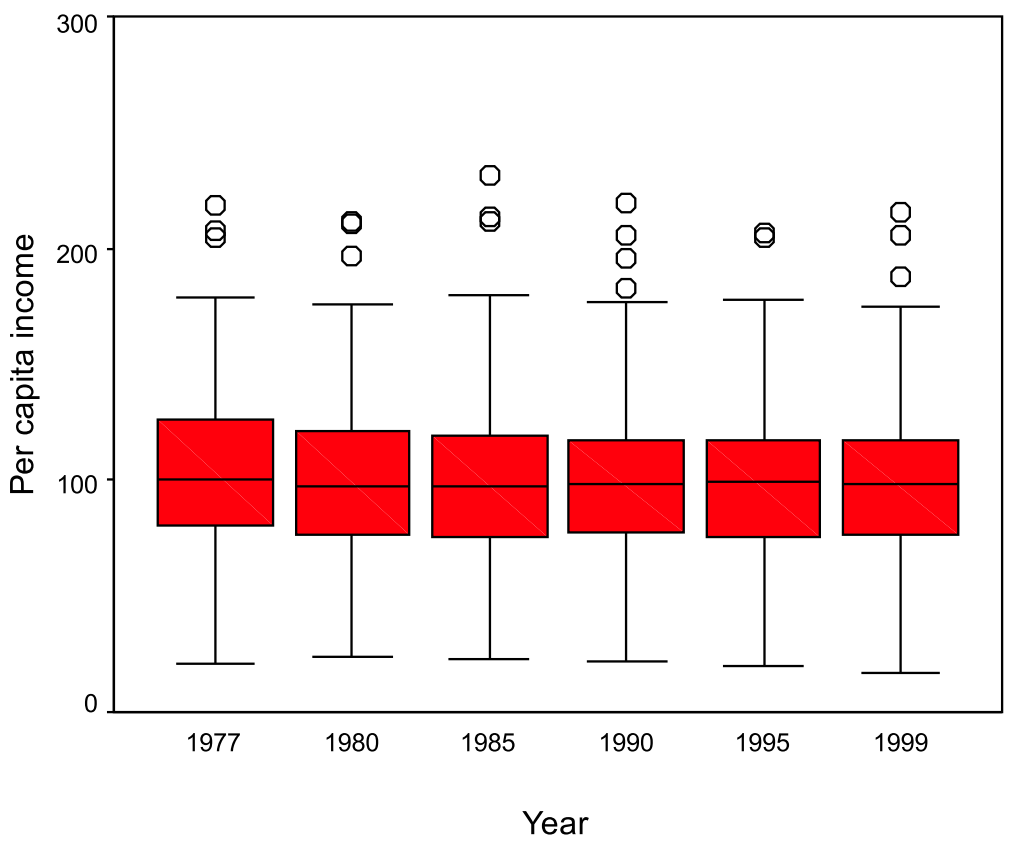

Table A1 : Relative population (\%) by per capita income levels (EU15=100).

\begin{tabular}{c|ccc} 
Income & $50-150$ & $60-140$ & $75-125$ \\
\hline 1977 & 80.41 & 66.83 & 54.97 \\
1980 & 84.91 & 74.95 & 55.72 \\
1985 & 82.45 & 78.74 & 55.52 \\
1990 & 85.87 & 79.66 & 59.39 \\
1995 & 86.29 & 81.07 & 59.32 \\
1999 & 86.74 & 80.64 & 59.05 \\
\hline
\end{tabular}


Figure 3: Density functions of the regional per capita income distribution.
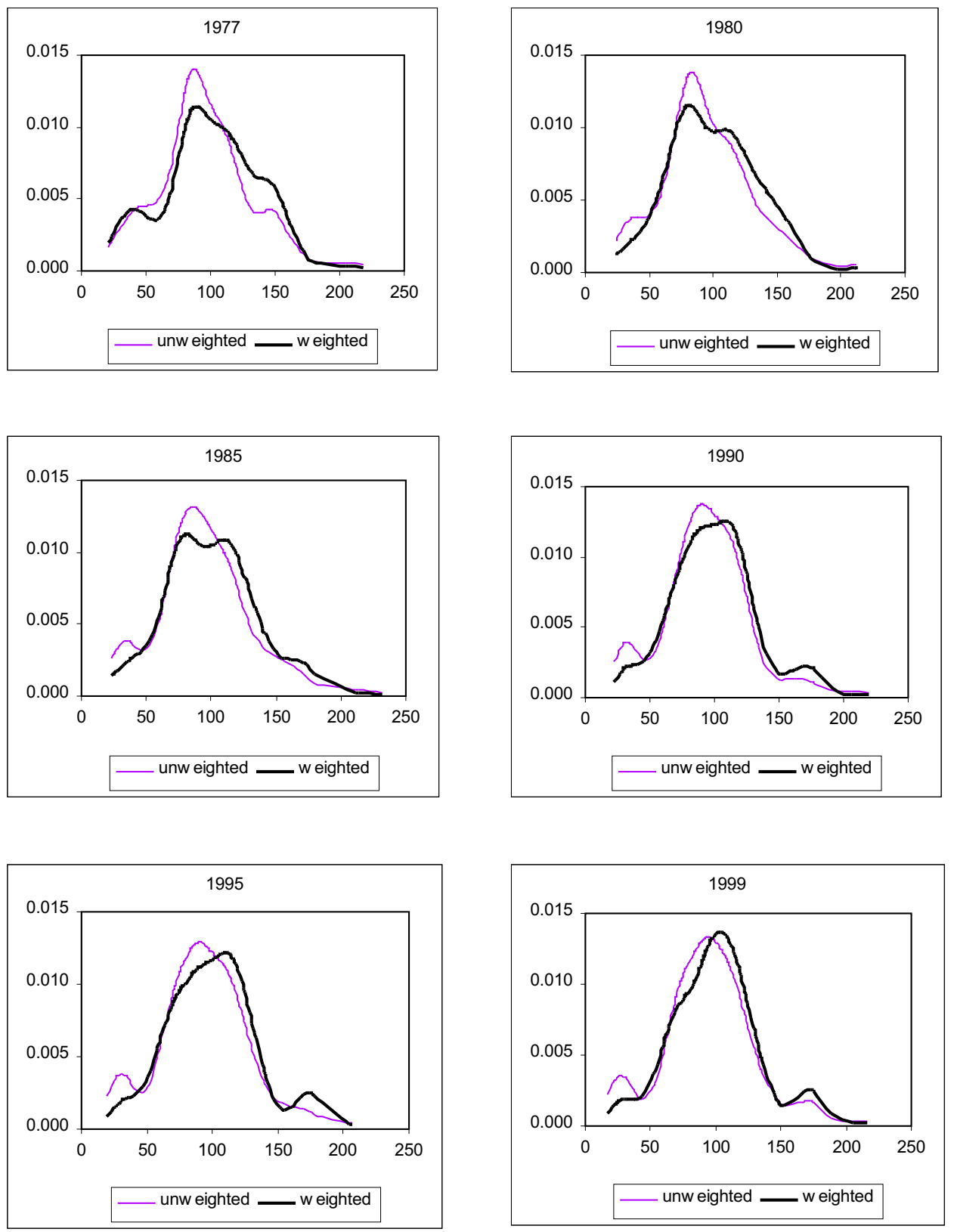
Figure 4: Regional polarisation: two groups $(1977=100)$.

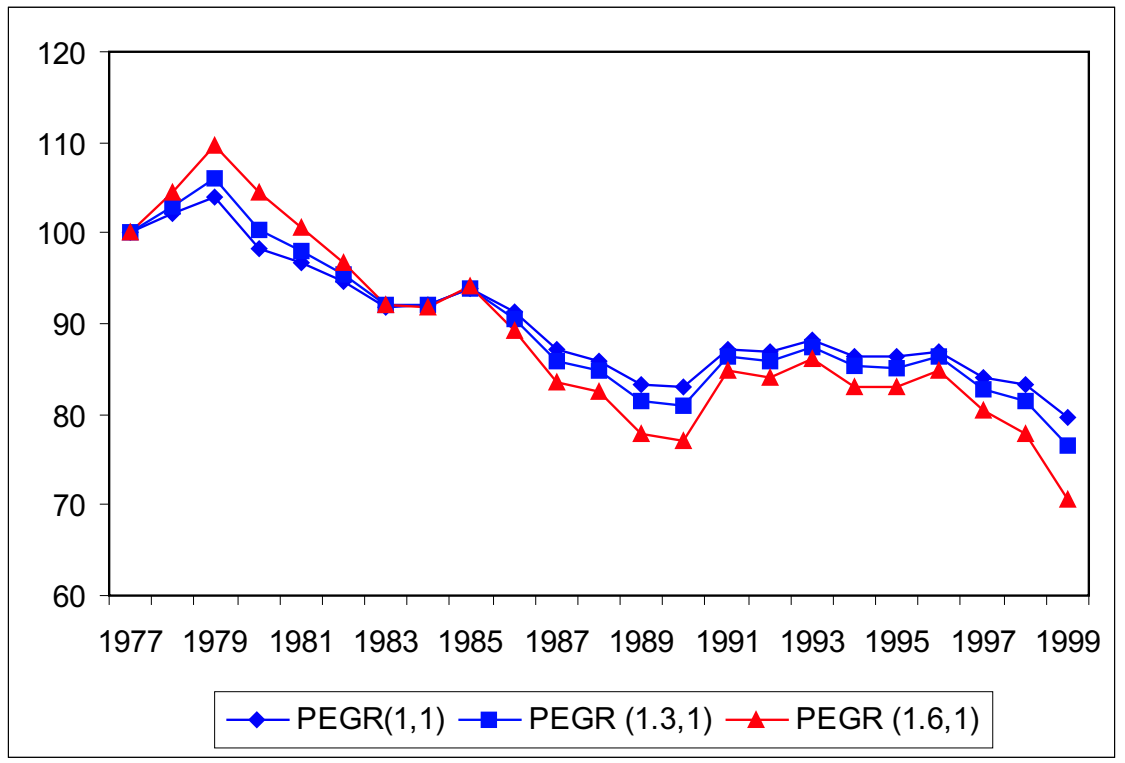

Figure 5: Regional polarisation: three groups $(1977=100)$.

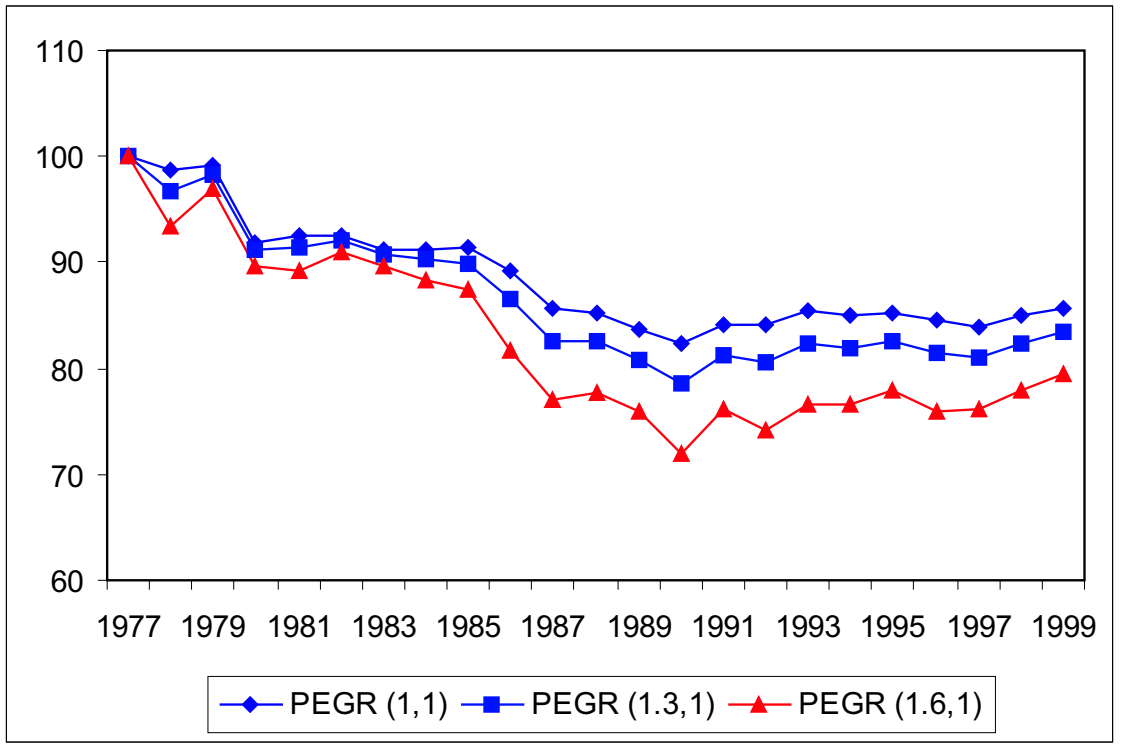


Figure 6: Stochastic kernel and contour plot of the regional per capita income distribution, 1977-1999.

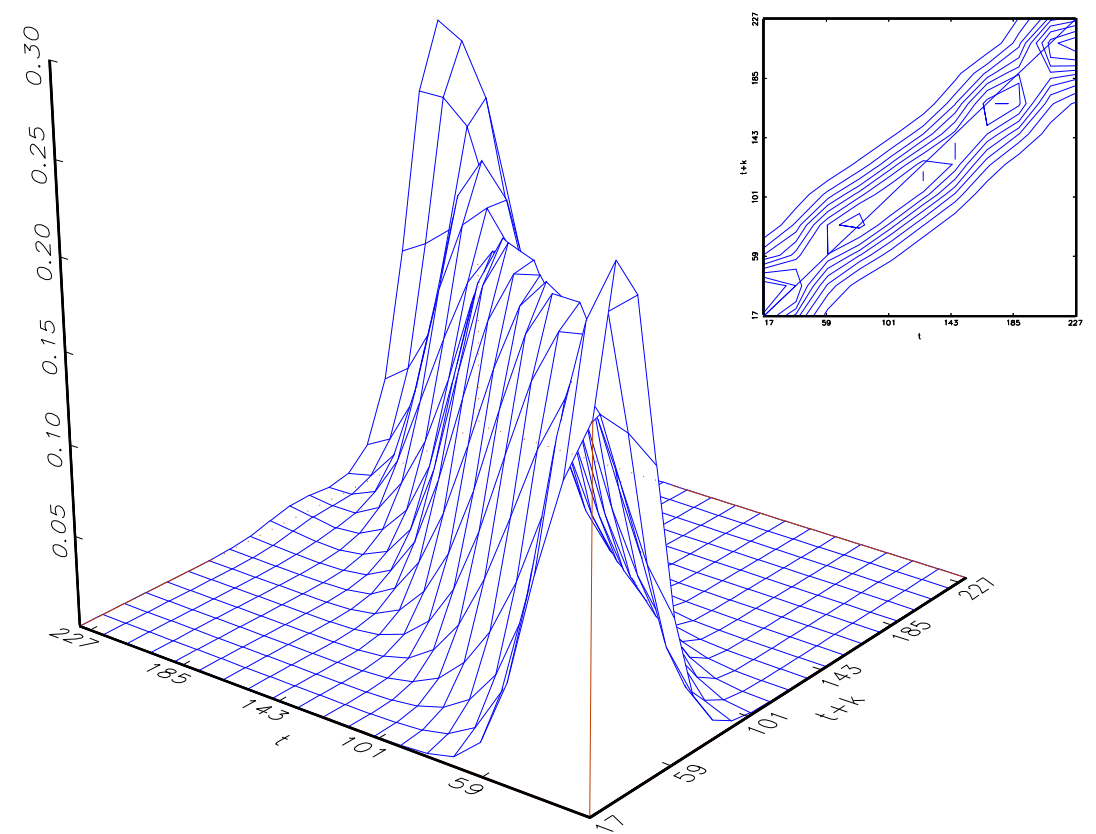

Figure 7: Ergodic distribution of the regional per capita income.

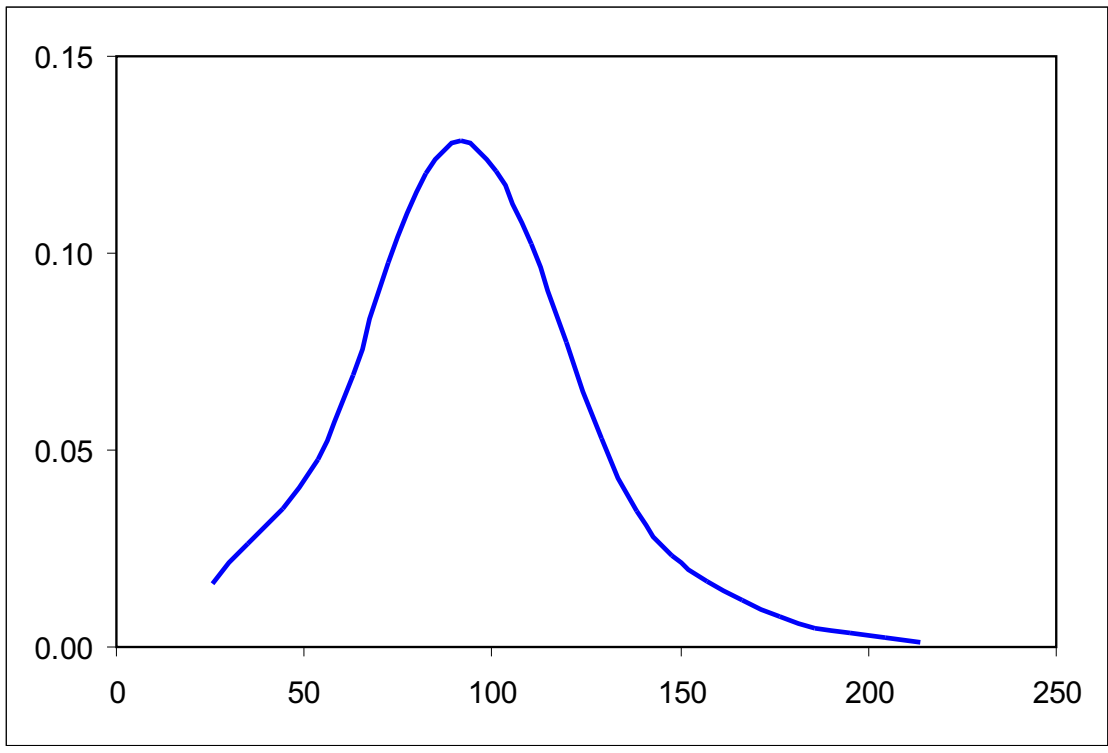


Figure 8: The national component and the distribution dynamics.

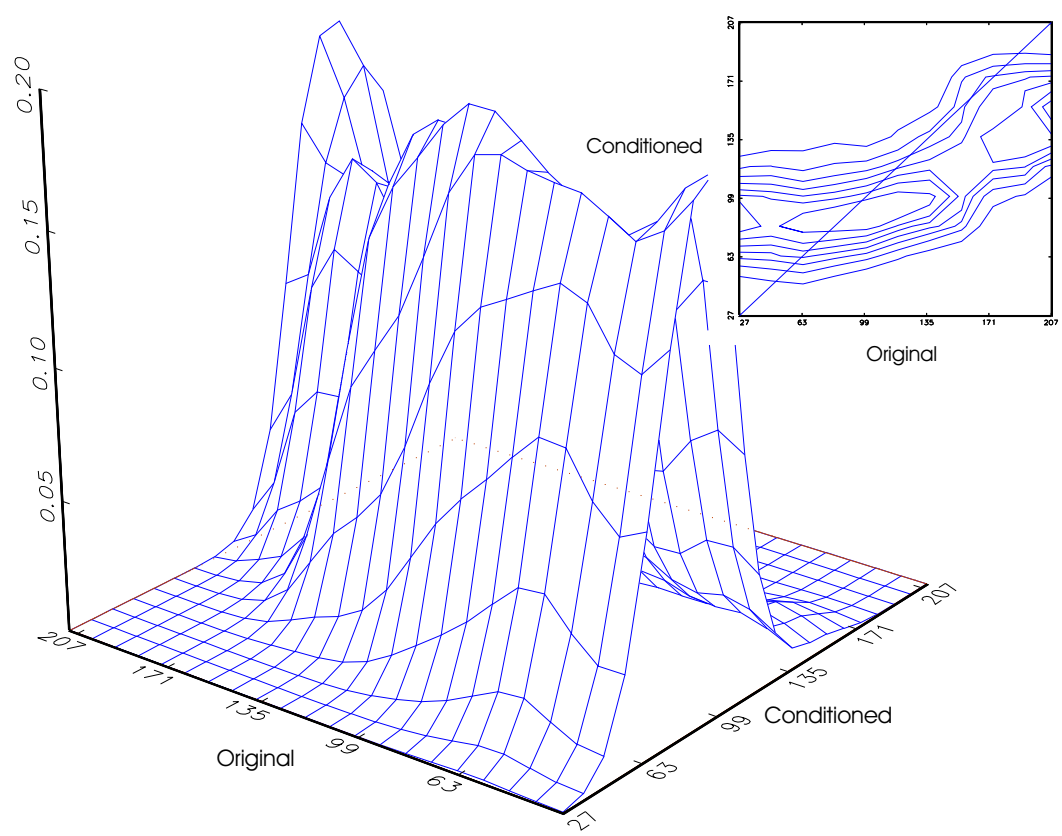

Figure 9: The spatial dimension and the distribution dynamics.

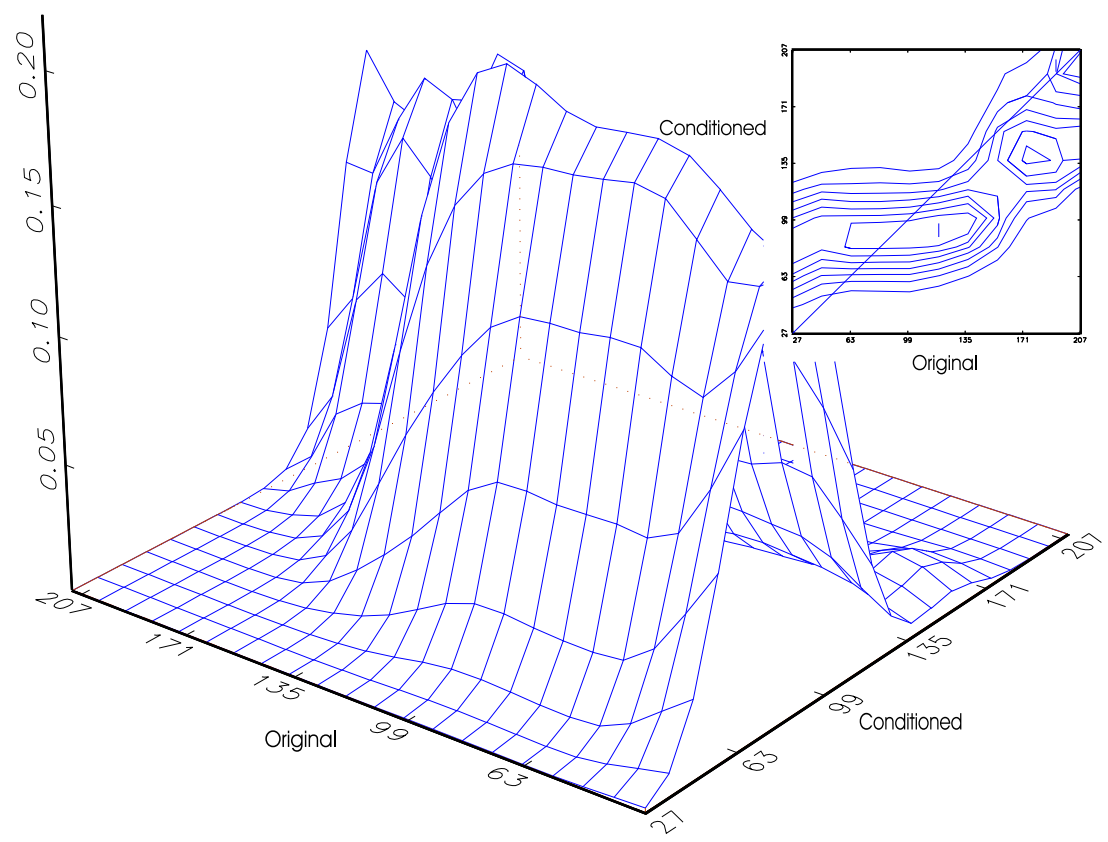


Figure A1: Sigma convergence. (Data unweighted according to population shares.)

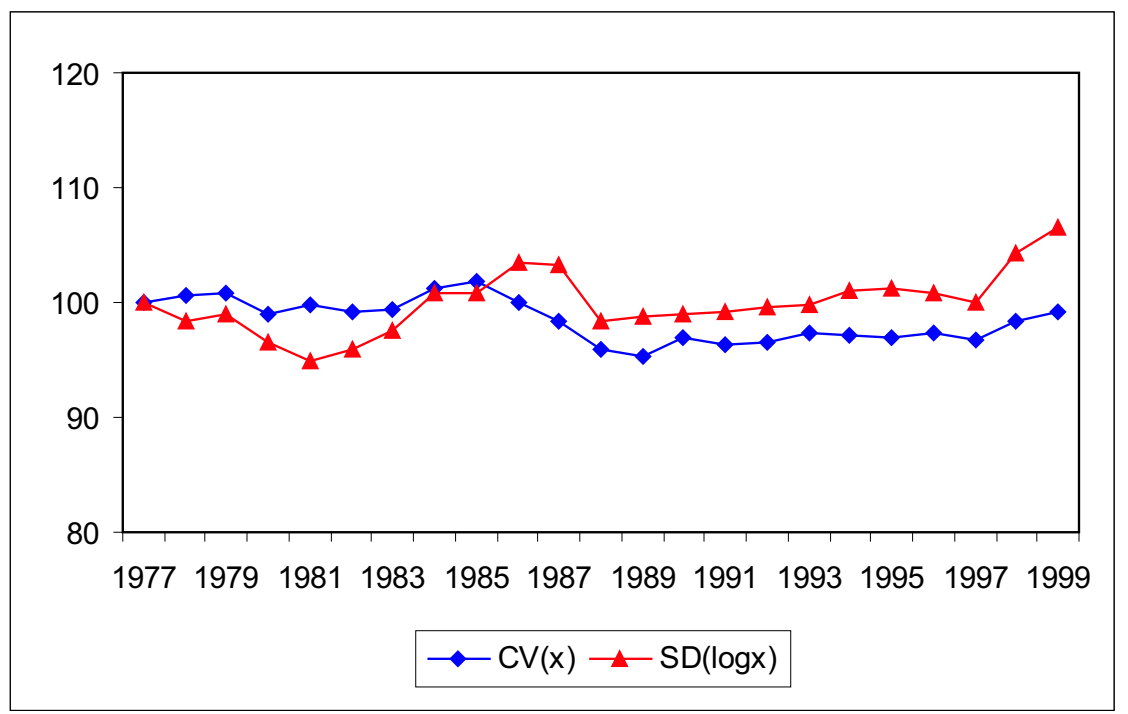

Figure A2: The national component, the spatial dimension and the distribution dynamics.

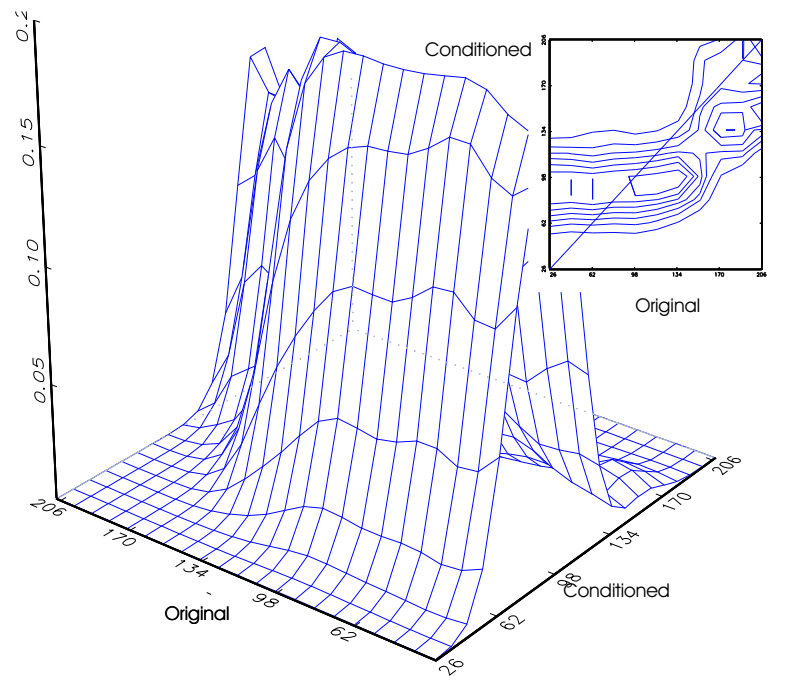

